\title{
FICÇÃO E SOCIALIZAÇÃO: UMA METÁFORA EM VIDAS SECAS, DE GRACILIANO RAMOS
}

\section{FICTION AND SOCIALIZATION: A METAPHOR IN GRACILIANO RAMOS'S BARREN LIVES}

Henrique Carvalho Pereira

RESUMO: O presente ensaio tem como objetivo ler um trecho de Vidas Secas, de Graciliano Ramos, a partir de uma perspectiva retórica. Trata-se da passagem na qual o patriarca da família, Fabiano, hesita quanto à própria denominação metafórica. Com isso, pretende-se esboçar uma análise sobre a relação entre o ficcional e o político no pensamento desse autor. Para tanto, exposição foi dividida em dois momentos. No primeiro, expôs-se a interpretação que serve de base para esta, um exercício semeIhante feito por Paul de Man sobre o "Ensaio sobre a Origem das Línguas", de Jean-Jacques Rousseau. Em seguida, leu-se o tredifere da versão can difere da versão canonica segundo a qual a ficção de Graciliano se apresenta como representação imediata de questões sociais, reflexo de padrões mais amplos de consciência histórica ou condensação simbólica de uma experiência coletiva. Por outro lado, a visão proposta de maneira alguma torna essa ficção apolítica.

PALAVRAS-CHAVE: Vidas Secas; Graciliano Ramos; Retórica; Linguagem figurada; Paul de Man.

\author{
* pereirahenriquec@gmail.com \\ Mestre em Letras: Estudos Literários pela Universidade Federal de \\ Minas Gerais (Belo Horizonte - MG).
}

ABSTRACT: The present essay is aims at reading an excerpt from Graciliano Ramos's Barren Lives from a rhetorical perspective. I refer to the passage in which Fabiano, the family patriarch, hesitates on his own metaphorical denomination. This is intended to outline an analysis on the relation between fiction and politics in the author's thought. For this end, the exposition has been divided into two moments. Initially, I have shown the interpretation on which mine is based, that is, a similar exercise carried out by Paul de Man over Jean-Jacques Rousseau's "Essay on the Origin of Languages." Afterwards, I have read the selected passage from Graciliano Ramos. The comprehension I have reached difwich fers from the canonical version according to which Graciliano's fiction presents an immediate representation of social issues, reflex of wider patterns of historical consciousness, or as the symbolic condensation of a collective experience. On the other hand, the proposed view in no way makes this fiction apolitical.

KEYWORDS: Barren Lives; Graciliano Ramos; Rhetoric; Figura language; Paul de Man. 
A leitura feita por Paul de Man sobre Rousseau na segunda metade de seu Allegories of Reading (DE MAN, 1979, pp. 135-301) se inicia com uma análise concentrada sobre a metáfora e o papel político da ficção. Esse é um dos textos mais ricos do autor, e tem como um de seus vários méritos a identificação da unidade entre a teoria política e a teoria da literatura propostas por Rousseau sem permitir que essa identificação recaia em um idealismo. De qualquer forma, esse texto importa aqui principalmente pela maneira como de Man entende a linguagem metafórica e, por extensão, a da literatura, modo político da linguagem por excelência, como ele mesmo a define (cf. DE MAN, 1979 , p. 157). Gostaria de complementar essa reflexão com a breve análise de uma metáfora central no clássico Vida Secas, de Graciliano Ramos (1965). Antes de partir para o trecho de Graciliano Ramos, porém, importa expor em maior detalhe a discussão levantada por de Man.

O capítulo "Metaphor (Second Discourse)" parte da dificuldade em se precisar o estatuto retórico do "Discurso sobre a Origem da Desigualdade" no corpus de Rousseau. De Man identifica como responsável por essa dificuldade a passagem do texto sobre a origem da linguagem, recurso à ficção que produz ampla discordância no interior da fortuna crítica quanto a seu estatuto referencial. Para analisá-lo, o autor mostra um panorama da recepção de
Rousseau e da leitura canônica com o intuito de localizar com precisão o problema. Então, desafia essa interpretação identificada como canônica a partir de uma leitura retórica do trecho chave. Em sua leitura, de Man percebe que a faculdade linguística da conceptualização é descrita por Rousseau segundo uma estrutura tropológica na qual um processo metafórico substitui um metonímico. $\mathrm{O}$ mundo natural, em Rousseau, aparece como pura contiguidade, uma sequência de singularidades percebidas pelo homem primitivo (logo é descrito metonimica mente por Rousseau), e então conceptualizado a partir da substituição dessa visão metonímica por uma metafórica. Nesta, identificam-se semelhanças entre as coisas contíguas e se as agrupam sob as mesmas ca tegorizações. A denominação e a conceptualização são opostas de maneira antitética respectivamente como linguagem literal e figurativa. "Isso permite", afirma de Man, "uma valorização que privilegia um modo sobre o outro" (DE MAN, 1979, p. 146; nossa tradução) ${ }^{1}$, mesmo que de maneira implícita. No caso, a linguagem literal sobre a figurativa. Rousseau é normalmente lido dessa forma embora isso gere conflito com a firmações suas, como, por exemplo, a de que a primeira linguagem teve de ser figurada. Essa leitura também permite ver a passagem ao uso retórico da linguagem, a literatura, como sendo a passagem da necessidade de se nomear o mundo à necessidade figurativa de se nomear a si próprio em correlação com o mundo.
1. "This allows for a valorization hat privileges one mode over the

2. Cf. ROUSSSEAU, 1999, pp. 267 8. O capítulo que cito corresponde ama tradução, em português, do 
3. "It is impossible to say whether denomination is literal or figural". 4. Transcrevo a maneira como este episódio aparece na traducăo em português: “ “Un nicialmente ter-se-in amedronta outros terror tê-lo-ia levado a ver esses homen maiores e mais fortes do que ele próprio dar-hes o nome de gigantes. Depois suitas experièncias, reconheceria que, nà nem mais fortes do que ele, à sua estatura não convinha a ideia que a princípio ligara a palavra gigante. Inventaria, pois
um outro nome comuma eles ea si proprio, como, por exemplo, o nome homem deixaria $\mathrm{o}$ de gigante para $\mathrm{o}$ falso objeto

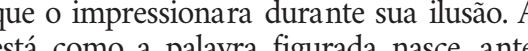
da própria, quando a paixão nos fascina o thos e a primeira idela que nos oferece nàa a da verdade. O que disse a respeito das torneios de aprase Apresentando-se em primeiro lugar, a imagem ilusória ferecida pela paixão, a linguagem que nventada: depois tornou-se a primeir inventada; depois tornou-se metaforic
quando o espirito esclarecido, reconhecendo eu próprio erro, só empregou as expressōo (ROUSSEAU,1999,pp.267-8, meusnegritos) Veja-se como a linguagem figurativa definida por Rousseau não apenas como riginal, mas também como uma relacão do gação se deve à ilusão passional. Compar esta traducão com a que foi feita por Paul de Man e sua esposa, Patricia de Man, para o ingless: "A primitive savage, on meeting one of
his own kind, will first of all experience fear. His fear will cause him to see these human beings as taller and stronger than he is; he wil experiences, he will come to the conclusio hat, since those assumed giants are neithe taller nor stronger than he is himselff their originally linked to the word 'giant' He will therefore invent another name, commo to both, such as for instance the name man and leave giant for the aberrant object that
Após expor a interpretação tradicional, de Man questiona se seria mesmo esse o caso. Pareceria, na verdade, que, para Rousseau, a linguagem figurativa ou conceptualização estaria embutida na linguagem descritiva ou literal, e "é impossíve dizer se a denominação é literal ou figura tiva” (DE MAN, 1979, p. 148; nossa tradução) ${ }^{3}$. Isso leva de Man ao exame da parábola de Rousseau na qual o homem primitivo se defronta com outros homens iguais a ele, sente medo, nomeia-os como "gigantes" e, depois, ao conhecê-los melhor, medir-se em relação a eles, substitui o nome "gigantes" por "homens", no qual ele mesmo se encaixa. ${ }^{4} \mathrm{Na}$ leitura feita por de Man, essa alegoria ${ }^{5}$ se inicia pelo deslocamento de um sentimento subjetivo (e por isso em nada incorreto em sua descrição) para um nome exterior, fundado esse desloca mento em uma desconfiança quanto às aparências. Isto é, o medo se manifesta no primeiro nome em razão de o homem primitivo desconfiar que, mesmo os seres que ele vê se assemelharem a ele, pode ser que não se comportem como tal e apresentem perigo. A primeira denominação, portanto, parte de um sentimento de desconfiança quanto à correspondência entre interioridade e exterioridade. Essa desconfiança é uma hipótese permanente, que não pode ser verificada. Isso afirma a prioridade da metáfora sobre a denominação, mas também complica a estrutura desse tropo. Ele é verdadeiro na medida em que adequadamente expressa um sentimento de medo, mas errôneo quando equaciona no interior do mesmo nome (ou metáfora) uma verdade subjetiva a uma imprecisão objetiva.
É verdadeiro em sua coerência interna, formalmente como ficção, mas não na coerência referencial - movimento, aliás, que desloca o sentimento e sua validade referencial para a estrutura linguística da ficção. A metáfora enquanto ficção consiste na afirmação dessa condição que substitui uma situação referencial suspensa entre fato e ficção pelo que seria o fato referencial. Logo, com o intuito de vir a ser, a figura da metáfora deve se desfigurar, ou seja, ser tomada como literal e desfazer sua verdadeira coerência ficcional.

Antes de continuar a leitura do texto, cabe expor em maior detalhe no que consiste a estrutura da metáfora analisada até aqui. De Man havia notado na leitura de Rousseau que a metáfora possui dois lados: um verdadeiro e o outro não necessariamente falso, mas inverificável. O verdadeiro diz respeito à sua coerência interna, à dimensão na qual ela responde apenas a si mesma. No exemplo de Rousseau, a afirmação de que os outros homens são "gigantes", nome que implica a ameaça, irracionalidade e comportamento agressivo contra o qual o sujeito é incapaz de triunfar ileso, é verdadeira com relação ao medo que ela expressa. O outro lado está suspenso entre verdade e falsidade em uma afirmação que não pode ser logica mente verificada. Pode ser, sim, que os outros homens, embora tenham mais ou menos o mesmo tamanho de nosso protagonista, venham eventualmente a ameaçá-lo. A suspeita quanto à falta de correspondência entre aparência e delusion. This is how the figure is born prior to the proper word, when passion fascinates this passion is not that of truth. What I have said here about words and names can easily be extended to turns of phrase. Since the to appear, the language that corresponts to appear, the language that corresponds
to this image is this first to be invented. Later on, it became metaphorical, when the enlightened mind, recognizing its original the passions that produced it in the first place." (DE MAN, 2016, p. 188). Por fim, vejase o trecho original " "Un homme sauvage en
rencontrant d'autres se sera d'abord effereye Sa frayeur lui aura fait voir ces hommes plus grands \& plus forts que lui-même; il leur aura donné le nom de Géans. Après beaucoup dexpériences il aura reconnu que
ces prétendus Géans nétant ni plus grands ces pretendus Geanns nétant ni plus grands
ni plus forts que lui, leur stature ne convenoil point à lídée quilil avoir d'abord attachée au mot de Géant. II inventera donc un autre
nom commun à eux \& à lui, tel par exemple que le nom d' Homme, \& laissera celui de Géant à lobjet faux qui l'avoit frappé durant son illusion. Voilà comment le mot figuré
nait avant le mot propre, lorsque la passion nous fascine les veux, \& que la première idée qu'elle nous offre n'est pas celle de la vérite. Ce que jai dit des mots \& des nom est sans difficulté pour les tours de phrases
L'image illusoire offerte par la passion, montrant la première, le langage qui lui repondoit fut aussi le premier invente; devient ensuite métaphorique quand l'esprit
éclaire, reconnoissant sa premiere erreur eclaire, reconnoissant sa premiere erres
n'en employa les expressions que dans les mêmes passions qui l'avoient produite
(ROUSSEAU, 1996 p. 366).

5. O nome é visto por de Man como cabível primeiro por se tratar de uma estrutura tempora sequencial e narrativa, e,

cena manifesta que se estabelece em relação figurativa com um significado para o qual existe uma "chave". 
conteúdo não está nem certa nem errada, posto que também pode ser que os outros homens se identifiquem afinal com o primitivo e eventualmente apresentem comportamento afável. Mesmo a suposta verificação a partir da aproximação, com o que o primeiro nome será necessa riamente substituído por outro, produz outro nome estruturado sobre outro sentimento (poder-se-ia chama-lo "segurança"), logo repete a estrutura problemática da metáfora precedente. Pode-se acrescentar, enfim, que a única coisa operada pela substituição da linguagem figurada pela literal é a inversão, na forma de outro tropo (quiasmo, a inversão simétrica de propriedades opostas), com o que o literal nada mais é do que a figura do figurativo. Isto é: o segundo nome, "homens", apresentará as mesmas contradições do primeiro, "gigantes", trocadas simetrica mente, sem alterar a situação que aparenta corrigir. Pa ra que ele venha a se estabelecer e o literal não seja visto como a figura da figura que ele é, torna-se necessário que a estrutura dupla a partir da qual ele se estabelece se desfaça, logo que seu estatuto como figura se desfigure. Isso ocorre quando a contribuição de outros frutos da percepção permite que se ignore a coerência interna inicial da metáfor como ficção e se assuma que seu lado incerto é totalmente verificável. Isto é, o homem primitivo então entra em contato com os outros homens e crê que de fato ou ele estava certo em ter medo ou estava errado. No primeiro caso, o nome "gigantes" se desfigura: deixa de ser metáfora e se torna literal.
No segundo, uma outra metáfora é sobreposta à primeira: esses homens são iguais a mim (hipótese permanente), logo é possível criar um nome que sirva tanto para mim quanto para eles, o nome homem. A estrutura da metáfora, portanto, consiste na união entre um lado certo e interna mente coerente (no primeiro caso, "estou com medo", no segundo "chamome de homem") e outro lado incerto, mas não incorreto, porque inverificável (no primeiro caso, "estes homens são ameaçadores", no segundo, "são igua is a mim"). Com o intuito de se realizar, a metáfora deve ser desfigurada na presunção de verdade daquilo que está, de fato, suspenso. A distinção entre literal e figura tivo assume, portanto, a possibilidade de se distinguir entre coerência interna e externa, o que é um erro dado que ambos surgem coextensivamente. Mais do que isso, suas estruturas são perfeita mente intercambiáveis. Contudo nenhuma linguagem pode existir sem esse erro.

A análise, para de Man, não pode parar aqui. De Man adverte sobre a necessidade de se notar que "o modo narrativo da passagem [de Rousseau] é ele mesmo uma metáfora que não deve nos induzir ao erro [mislead] de transpor uma estrutura linguística, sincrônica, para um evento histórico, diacrônico" (DE MAN, 1979, p. 152)6. A questão que surge é por que Rousseau opta pelo exemplo de um confronto isonômico (homem vê homem) para falar da linguagem. A resposta é simples: porque a linguagem conceitua precisamente a partir
6. "The narrative mode of mousseau's] passage is itself a us into transposing a synchronic, linguistic structure into a diachronic, historical event." 
do desloca mento de um processo linguístico em nome de outro igualmente linguístico. Como na estrutura da metáfora exposta acima, aquilo que se sobrepõe a uma unidade linguística é outra unidade linguística. Assim, a relação especular entre duas coisas que pertencem à mesma categoria é paradigmática para se tratar da linguagem. Isso significa que, para Rousseau, a denominação deriva da determinação da conceptualização e, como tal, o literal não passa de "uma figura oculta, cegada [escondida: blinded]” (DE MAN, 1979, p. 153; nossa tradução) ${ }^{7}$.

Consequentemente, a figuração ou conceptualização é, a princípio, a emergência de uma nomeação aleatória que funde um estado de coerência interna a um de imprecisão externa. Essa nomeação ocorre em sua forma específica ("gigantes") por acaso, e é tributária do potencial retórico da linguagem antes de ser uma conclusão lógica tomada da comparação entre várias metáforas. A conceptualização nasce da união entre o certo e o incerto, e só se concretiza a partir da desfiguração desse esquema. Isso significa que

O conceito de homem é então dupla mente metafórico: consiste primeiro no momento cego do erro passional que leva à palavra "giga nte", em seguida no momento de erro deliberado que utiliza o número [para Rousseau, igualmente incerto e metafórico] com o intuito de apaziguar a metáfora original e torná-la inofensiva (seja bem entendido que essa terminologia do "primeiro", "dupla mente", "original” etc., é ela própria metafórica e utilizada apenas pela clareza da exposição). O homem inventa o conceito de homem por meio de outro conceito que é ele próprio ilusório. A "segunda" metáfora, que Rousseau equaciona ao uso literário, deliberado e retórico da figura espontânea, não é mais inocente: a invenção da palavra homem possibilita que "homens" existam a partir do estabelecimento de uma igualdade dentro de uma desigualdade, o mesmo dentro da diferença da sociedade civil, na qual a verdade suspensa e potencial do medo original foi domesticada pela ilusão de identidade. (DE MAN, 1979, pp 154-5; nossa tradução) $)^{8}$.

Esse processo figurativo de desfiguração, descrito quanto à estrutura da metáfora, é, afinal, o que permite, para Rousseau, a existência da sociedade. Não as relações de trabalho que a caracterizam e produzem sua história, mas o próprio contato entre os homens no qual essa produção se opera. A sociedade civil nasce da literalização de metáforas violentas que sobrepõe outras metáforas literalizadas. Esse segundo movimento da conceptualização é uma reversão do primeiro. A princípio, a metáfora se origina de uma desconfiança quanto à correspondência entre interior e exterior. Em um segundo momento, outras metáforas substituem a primeira e são desfiguradas, tornadas literais, pela confiança nessa correspondência. Esse é o fundamento linguístico da lei e da sociedade civil, mas é também o mecanismo do uso deliberado
8. "The concept of man is thus doubly metaphorical: it first consists of the blind moment of passionate error that leads to the word 'giant, then of the moment of in order to tame the original wild metaphor into harmlessness (it being well understood that this numerical terminology of 'first' 'doubly,' 'original,' etc., is itself metaphorical and is used only for the clarity of exposition). Man invents the concept man by means of another concept that is itself illusionary. The 'second' metaphor, which Rousseau equates with the the of the spontand figure is no longer innocent: the invention of the word man makes it possible for 'men' to exist by establishing the equality within inequality, the sameness within difference of civil society, in which the suspended, potential truth of the original fear is domesticated by the illusion of dentity." 
da figuração, a literatura. Além disso, ele consiste não apenas na substituição da diferença pela igualdade, mas também em um falseamento proposital, a literalização da metáfora. Como se trate de uma sobreposição do uso retórico da linguagem, Rousseau a chama de linguagem literária. Isso leva de Man a concluir que a literatura é o modo político da linguagem por excelência - não por ela intervir de fora na sociedade, mas po ela reproduzir o gesto pelo qual se inauguram os termos da civilidade. Assim como a linguagem, a sociedade só pode existir a partir de um impulso forçoso que o homem não controla, se consolidar com base em distorções no interior desse modelo externo à consciência.

A literatura e as ficções são o modo político da linguagem por excelência precisamente porque a sociedade civil emana de uma ficção e da literalização de uma ficção. Coerentes em si, ficções se tornam não apenas frágeis, mas ideológicas, a partir do momento em que são transpostas para conceituar "do lado de fora" de sua coerência própria e referir a algo, já que não passam de hipóteses permanentes. Sem esse movimento, porém, nenhuma lei ou sociedade civil pode existir. Daí a inerente corruptibilidade do contrato social. Essa é uma das instâncias nas quais a ideologia, definida por de Man em outro ensaio como a "confusão da realidade linguística com a natural, da referência com o fenomenalismo" (DE MAN, 1986, p. 11; nossa tradução) ${ }^{9}$, é indissociável de toda socialização e de todo uso da linguagem.

O mais importante de se enfocar nessa análise não é tanto os aspectos políticos da teoria literária, mas a estrutura frágil, errônea, mas inevitável, da metáfora. A figuralidade que permite à linguagem conceituar é uma faca de dois gumes, um processo no qual é impossível manter a conotação figurativa separada da referência literal; por outras palavras, distinguir a hipótese (no caso exemplar, "temo que estes possam ser gigantes") do fato ("temo"). Crer na correspondência da referência linguística é um erro, mas inevitável. A literalização da figura sobreposta à primeira figura (processo que também depende de se tomar a primeira literalmente para que se possa julgar se ela é verdadeira ou falsa) permite que haja conceptualização e denominação. Entretanto, ele também permite que a estabilidade sobreposta pela "segunda" metáfora seja constantemente ameaçada por uma recaída no estatuto de "mera figura". Esse processo, por sua vez, está igualmente sujeito às mais aberrativas literalizações, já que a primeira literalização também é de certa forma aberrativa (posto que assume como fato o que não passa de hipótese). Uma vez que a sociedade se funda nesse processo, ela está sempre sob a constante ameaça de ser pervertida ou mesmo dissolvida. Não apenas a lei e a sociedade civil, mas todo tipo de conceituação se funda precisamente na mesma estrutura que permite sua
9. "[...] of linguistic with natural reality, of reference with phenomenalism. 
corrupção. Trata-se da dimensão figurativa da linguagem, e todos os escritos de Rousseau estão fundados em sua teoria da linguagem figurativa.

No romance Vidas Secas, de Graciliano Ramos, há um cena que se assemelha muito a esta de Rousseau e cujas particularidades podem oferecer um caso interessante de análise. Trata-se do famoso trecho do capítulo II, "Fabiano", no qual o patriarca, descansando após um dia de subsistência, hesita em se denominar ou como homem ou como bicho. A crítica literária tende a ser mais ou menos unânime quanto à significação deste trecho. Luan Alves Monteiro Carlos e La rissa Cristina Viana Lopes interpretam essa nomeação de Fabiano como "bicho" como sendo o "retrato" do sertanejo pobre em geral, capaz de vencer dificuldades (CARLOS; LOPES, 2012). Marli Fantini Scarpelli entende a passagem como afirmação de uma "adaptação 'genética' dos viventes de Vidas Secas ao meio ambiente"; para a autora, este seria um momento no qual linguagem consolida esse devir, manifesta essa continuidade (SCARPELLI, 2007, p. 198). Já Antonio Candido (2006), ao destacar a forma descontínua desse romance, nota que o narrador de Vidas Secas não busca uma imitação da realidade, mas "institui a humanidade de seres que a sociedade põe à margem” (CANDIDO, 2006, p. 149). A recusa de transpor a si o nome "homem" por parte de Fabiano seria, portanto, uma maneira de reafirmar essa exclusão, mas nomear-se mesmo assim, como se as palavras das quais dispõe não lhe pertencessem.

Vamos ao trecho. Em um momento de satisfação com o sucesso do próprio trabalho, Fabiano inaugura uma reflexão sobre sua própria identidade e seu papel no mundo. Sem motivo aparente, diz:

- Fabiano, você é um homem, exclamou em voz alta. Conteve-se, notou que os meninos estavam perto, com certeza iam admirar-se ouvindo-o falar só. E, pensando bem, ele não era homem: era apenas um cabra ocupado em guardar coisas dos outros. Vermelho, queimado, tinha os olhos azuis, a barba e os cabelos ruivos; mas como vivia em terra alheia, cuidava de animais alheios, descobria-se, encolhia-se na presença dos brancos e julgava-se cabra.

Olhou em torno, com receio de que, fora os meninos, alguém tivesse percebido a frase imprudente. Corrigiu-a, murmurando: - Você é um bicho, Fabiano.

Isto para ele era motivo de orgulho. Sim senhor, um bicho, capaz de vencer dificuldades. (RAMOS, 1965, p. 20-21).

O trecho parece retratar um momento de conformação, na denominação, de uma posição social que se desenhara 
no trajeto de Fabiano. Bem como no restante do livro, o patriarca é um homem analfabeto que tem dificuldade em se expressar (outro episódio significativo disso seria o encontro com o soldado amarelo). Neste momento, é como se Fabiano estivesse diante do espelho se reconhecendo e a tribuindo à sua interioridade a identificação perfeita com uma série de sinais encontrados no exterior. Igual ao bicho, o retirante nordestino simbolizado pela família que protagoniza Vidas Secas passa por um caminho cíclico que se repete infinitamente. Essa é uma família que existe, em várias de suas versões, no mundo real, todas elas condensadas nos viventes retratados por Graciliano Ramos. A disposição dos capítulos, justapostos em vez de contínuos, e a simetria (logo reversibilidade) entre o final e o começo da narrativa permite entender que a história inteira se repetirá assim que se encerrar, e que antes de começar a jornada no primeiro capítulo os viventes haviam passado por outra proporcional a ela. A geografia do sertão descrita por Graciliano seria uma prisão, mas também o habitat natural dos protagonistas.

Em contrapartida, assim como o bicho, que vive um processo cíclico, os humanos de carne e osso de Vidas Secas se adaptam ao meio a mbiente em uma celestial simbiose. $\mathrm{O}$ bicho, o animal, também analfabeto, tem um contato sem dúvida genético com a natureza, e suas origens coincidem essencialmente com suas características aparentes. $\mathrm{O}$ mesmo se dá quanto aos viventes retratados por Graciliano Ramos. O bicho, assim como Fabiano, desconhece a linguagem e como tal não pode se estabelecer em relação de determinação ou mediação com o mundo natural. Antes, seus instintos são indissociáveis do meio a mbiente. $\mathrm{O}$ animal cuida de seu habitat não por ter refletido e chegado à conclusão de que lhe será benéfico tal cuidado, mas porque ele vive em sintonia com a doce dança da natureza. Um tamanduá, por exemplo, não esgota de uma vez todas as formigas de sua região não porque seu pai ou sua experiência o tenham ensinado a ser prudente, tampouco porque mede sua fome para que ela coincida com o número certo de formigas da região. Antes, seu instinto sabe a hora certa de parar para que sobre alimento para o dia seguinte, e com isso o ciclo da natureza se retroalimenta assim como o ciclo de Vidas Secas ta mbém.

Por outro lado, o bicho também é uma forma de existência que se presta a ser dominada pelo ser humano. Assim como Fabiano e sua família nas mãos de Seu Tomás da Bolandeira (a bolandeira também sendo outro símbolo da ciclicidade, máquina que coisifica e aprisiona, tornando o homem objeto e não sujeito da tecnologia moderna, segundo João Batista Santiago Sobrinho ${ }^{10}$, do fazendeiro e do soldado amarelo. Justamente porque não domina a linguagem, logo se torna análogo ao bicho, o retirante é inscrito em um processo cíclico de dominação. Forçado a partir de uma terra sem recursos, aî 
inclusa a educação, torna-se sujeito a ser explorado no trabalho informal onde quer que se encontre. Por isso mesmo, o narrado de Vidas Secas não pode se encontrar com o protagonista da mesma forma como ocorre em Angústia ou São Bernardo, narrativas nas quais o narrador-protagonista é alfabetizado e dono de alguma coisa. Em Vidas Secas, ao contrário, os protagonistas não têm o controle sobre seus próprios destinos, principalmente por questões econômicas, e por isso não podem ser representados com controle sobre o meio a partir do qual sua história se desenrola, a linguagem. A nomeação de Fabiano como bicho o inseriria, embora de maneira oblíqua, nessa narrativa preservando o esvaziamento de sua subjetividade. Essa cena seria paradigmática, portanto, do reconhecimento problemático do sertanejo em seu caminho na sociedade brasileira e retrataria também o destino de todo um povo identificado com sua terra e sofrido em seus obstáculos tão específicos. Haveria assim uma equivalência entre a substância íntima do bicho e a de Fabiano que permitiria a permutação entre ambos, da mesma maneira como a família de retirantes significa toda uma experiência histórica da seca, do trabalho e da migração no coração do Brasil.

Uma leitura mais detida sobre a passagem deve demonstrar que nenhum desses casos está de fato ocorrendo em Vidas Secas. A própria maneira como esse processo é descrito contraria significação aparentemente sinalizada. Assim como o homem primitivo de Rousseau, Fabiano parece passar nesse trecho por duas denominações, uma segunda que corrige e substitui a primeira. Ainda mais do que em Rousseau, onde um homem se refere a outro homem (logo existe uma relação especular) Fabiano, que se refere à sua própria imagem refletida, está em uma situação onde a denominação implica em uma autodenominação. E ela não representa apenas a confirmação do papel social do indivíduo, mas mostra também como, por meio de uma metáfora e uma ficção, essa confirmação se produz. O trecho de Graciliano Ramos contém uma fala, um assunto e sua interpretação contidos no mesmo objeto. Afinal, quando Fabiano se contém por notar a proximidade dos meninos, nada no trecho leva a entender que estes estejam participando do ato de comunicação de qualquer modo. Pelo contrário, Fabiano evita se dirigir a eles, mas projeta sobre eles seu receio. Isso torna a cena paradigmática como a to linguístico de compreensão: Fabiano fala de Fabiano para Fabiano. O ciclo é esclarecedor quanto a todo uso linguístico. De certa forma, toda linguagem não deixa de ser sobre ela mesma, e o ato de enunciação por parte de Fabiano se torna assim uma tentativa de autocompreensão não apenas do sujeito, mas da própria linguagem.

Em um primeiro momento, Fabiano exclama, em voz alta, um período simples, com verbo de ligação, associando de maneira unívoca dois termos. Nesse primeiro momento, 
11. Aliás, de toda linguagem em si, uma vez que a linguagem como sistema de representação está fundada na possibilidade de um signo ou conjunto de signos poderem ser postos no lugar de conceitos ou objetos.
"Fabiano" é equacionado a "homem". Essa estrutura é distintiva de toda metáfora e de toda linguagem figurativa, que consiste basicamente no uso de uma coisa no lugar de outra ${ }^{11}$. "Homem" então é afirmado, por um ato arbitrário e desconexo quanto ao que vem antes, como nome que pode equivaler a "Fabiano", suprassumi-lo e representá-lo. O que motiva essa substituição? É um ato aleatório de postulação, que não carrega nenhuma ligação com o que precede. Antes do trecho citado, Graciliano Ramos coloca o seguinte:

[Fabiano] Pisou com firmeza no chão gretado, puxou a faca de ponta, esgaravatou as unhas sujas. Tirou do aió um pedaço de fumo, picou-o, fez um cigarro com palha de milho, acendeu-o ao binga, pôs-se a fumar regalado. (RAMOS, 1965, p. 20).

Imediatamente depois, Fabiano se denomina "homem". O ato de denominação, que funda toda linguagem figurada e, por extensão, toda linguagem (já que toda significação pode ser definida como a substituição de uma coisa por outra), ocorre por meio de uma ruptura. Em conformidade com isso está o estilo paratático do trecho e do romance inteiro, no qual imagens são justapostas em sequência. Nada anuncia que Fabiano irá se denominar nesse momento. Não há qualquer ligação causal, temática, sintática ou de qualquer outra natureza entre esse trecho e o posterior. A figura segundo a qual a segunda parte de um enunciado não completa a primeira, na retórica, se chama anacoluto. Após esse a nacoluto, fez-se o nome. Surgindo sem motivação, o nome "homem" pode apenas servir para categorizar algo que até então se encontra fora de qualquer categorização. Como tal, a atribuição do nome "homem" para significar "Fabiano" tem o aspecto de uma catacrese, a figura segundo a qual se estende o uso de um nome de maneira imprópria para algo que ainda não tinha nome. Ao inscrever essa interrupção em seu romance, Graciliano estaria repetindo ficcionalmente $\mathrm{o}$ ato que inaugura toda denominação, como se começasse de novo a linguagem. A primeira palavra que Fabiano associa a si mesmo, portanto, sua primeira linguagem, é figurativa como aquela descrita por Rousseau. E a atribuição desse nome é fruto de um ato aleatório, imprescindível e desconexo, o potencial retórico da linguagem.

Assim como o homem primitivo de Rousseau, Fabiano passa por um momento de reflexão ("E, pensando bem”), no qual busca um nome para substituir esse primeiro, que seja mais apropriado do que ele. Essa reflexão é motivada por um sentimento. Em Rousseau, ele precede a primeira denominação; em Graciliano, a segunda (muito embora seja possível dizer que os detalhes narrados antes da primeira denominação, no capítulo, constituam uma construção de pathos). Esse sentimento é narrado da seguinte forma: "[Fabiano] Contevese, notou que os meninos estavam perto, com certeza iam admirar-se ouvindo-o falar só”. Pode-se sumarizá-lo com um 
só nome também, "vergonha" - oposto ao pathos anterior, de orgulho. A vergonha leva Fabiano a procurar ser mais razoáve e encontrar outro nome segundo o qual se denominar. Após um momento de raciocínio, ele chega à palavra "cabra".

Implicitamente, "bicho" também pareceria estar associado ao ca minho cíclico dos viventes de Vidas Secas, que, assim como o bicho, repetem seu caminho incessantemente. Todavia não está totalmente claro se a relação entre "Fabiano" e "bicho" é de reflexo recíproco. "Bicho" entra para substituir e suplementar a insuficiência da denominação "homem". Fabiano pode se chamar "bicho", mas bicho não pode se chamar "Fabiano". Assim como "homem", "cabra" também é uma denominação figurativa. Embora surja após um momento de comparação e reflexão, não de uma postulação descontínua, ela não obstante substitui outra coisa que é seu significado. Enquanto "homem" surge como nome que se estende para referir algo ainda não categorizado ("Fabiano"), "bicho" faz o mesmo, mas vindo de um conjunto referencial focado em um objeto que não é isonômico quanto ao primeiro. Fabiano se compraz com essa denominação e a enuncia de forma menos retumbante, mas mais sincera e assertiva do que a palavra "homem": "Corrigiu-a, murmurando”. Esse murmurar é como um ato de confissão. Sendo assim, Fabiano sabia desde o início que não era um homem, logo sua primeira denominação foi uma ficção. No entanto a segunda denominação, afirmada como verdade, não deixa de ter a estrutura de uma ficção também, e uma muito mais complexa do que a primeira. O nome "cabra" é uma expressão nordestina para "homem", ou o que nós do sudeste chamaría mos de "cara", e pode ta mbém designar o trabalhador agrícola; mas designa inicialmente um animal. Ela comporta ao mesmo tempo a referência a homem e a animal, mas se mantém suspensa entre os dois - a situação angustiante na qual se encontra Fabiano. Não é possível designar ambos ao mesmo tempo, sendo necessária uma escolha em cada situação de uso da expressão. Além disso, sendo uma designação que entra no lugar de "homem", que nesse trecho já é uma metáfora para substituir "Fabiano", o nome "cabra" não se torna uma referência literal, mas a metáfora de uma metáfora. Ou melhor o literal já é em si uma metáfora que se abre a um abismo metafórico ainda mais profundo. "Cabra" substitui "homem", que substitui "Fabiano", mas esta última substituição é dita imprópria pela primeira. Assim, ao substituir uma metáfora por outra, Fabiano não chega a uma denominação literal de si, mas figurativa, e queima a ponte que faz a ligação com o próprio objeto que ele tentara designar em primeiro lugar.

O nome "bicho", murmurado na última linha do trecho citado, encerraria a cadeia de substituições. E ele o faz a partir de uma figura que caracteriza toda a cadeia de metáforas. "Bicho" não é uma metáfora para "cabra", mas uma sinédoque: "cabra" é um animal, logo uma parte do todo designado por "bicho". A 
metáfora inicial "homem" projetou uma alegoria inteira de figuras que agora se torna contra si mesma. Após a primeira metáfora, "homem", toda uma sucessão de substituições em um eixo horizontal, temporal, logo metonímico, sucede: "homem" é trocado por "cabra", que é trocada por "bicho". No primeiro caso, a substituição de "homem" por "cabra" é tão arbitrária quanto a de "Fabiano" por "homem". No segundo caso, não. Apenas aqui emerge o literal ("cabra" sempre é um "bicho") mas o literal surge como nome deslocado para o figurativo, sendo o literal já em si uma figura para o figurado ("bicho" para "homem"). E a sinédoque "bicho" surge na ponta de um eixo que já é metonímico, a sequência de substituições que vai de "Fabiano" a "bicho". Essa última denominação é seguida por sua confirmação, onde Fabiano confirma a aptidão do nome "bicho" três vezes:

Corrigiu-a, murmurando:

- Você é um bicho, Fabiano. [1]

Isto para ele era motivo de orgulho. Sim senhor, um bicho [2] capaz de vencer dificuldades.

$[\ldots]$

- Um bicho, Fabiano. [3]

Era. (RAMOS, 1965, p. 20-21)

Com o intuito de se afirmar como literal, não basta o nome "bicho" substituir figurativamente o nome "homem".
Seu caráter metafórico é reafirmado pelas definições dadas a "bicho". A característica definidora de "bicho", "capaz de vencer dificuldades", é equacionada às dificuldades narradas logo após a terceira afirmação.

Assim como a estrutura da alegoria projetada pela primeira metáfora, o ato de denominação nesse trecho de Graciliano Ramos não é tautológico, mas não deixa de ser uma repetição do mesmo, como se gaguejasse. Antes de ser a concentração dos nomes anteriores, "bicho" nada mais é, no caso, do que a repetição dos mesmos erros representados por esses nomes. Como visto, o trecho pode ser descrito como "Fabiano falando de Fabiano para Fabiano". Da mesma maneira, a história narra uma substituição arbitrária substituída por outra infinitamente, a té que essa sequência é temporariamente encerrada por um ato que se pretende motivado ("bicho" por sua parte "cabra"), mas é tão a rbitrário quanto aquele que abre a sequência em primeiro lugar. O trecho é uma alegoria do próprio ato de denominação, não a construção de um todo simbólico, e outra coisa que ele pode nos dizer é que toda metáfora como a to de denominação engendra alegorias de sua própria leitura. Isto porque o nome metafórico "homem" aplicado por Fabiano para substituir "Fabiano" acarreta sua própria leitura pelo próprio Fabiano, com o que ele é substituído por outro nome. A estrutura autorreflexiva "Fabiano falando sobre Fabiano 
para Fabiano" se dobra contra si mesma e produz apenas sua própria repetição. Entretanto é apenas por meio desse ato arbitrário de postulação que Fabiano é capaz de dar sentido a sua própria experiência e a seu próprio lugar social. Não é, porém, a postulação que dá sentido, mas a figura. Ainda assim, a interrupção desse ato não deixa de estar em erro, bem como a interrupção que o inaugurou. Esse é um erro sem o qual nenhuma compreensão e nenhuma socialização pode ocorrer. Enquanto Fabiano tenta impor nomes diferentes sob os quais se entender, o mecanismo da linguagem o força a uma repetição da mesma mecânica, colocando seu a to em contradição consigo mesmo e condenando-o a uma relação constantemente travada sobre a qual qualquer esforço seu é inútil. A crença em uma continuidade permite o desenvolvimento do enredo de Vidas Secas, mas esse desenvolvimento jamais supera o mecanismo repetitivo e gago no qual Fabiano foi inscrito. A máquina que aprisiona e coisifica Fabiano é muito mais antiga do que a tecnologia moderna denunciada de maneira tão convincente por João Batista Sobrinho (2014). E, ao contrário desta, ela não fo "inventada" pelo ser humano nem jamais esteve sob seu controle.

Ao se denominar "homem", então "cabra" e por fim "bicho", Fabiano encontra ma is do que seu próprio nome. Ele encontra seu papel no mundo:
Agora Fabiano era vaqueiro, e ninguém o tiraria dali. Aparecera como um bicho, entocara-se como um bicho, mas criara raízes, estava plantado. Olhou as quipás, os mandacarus e os xiquexiques. Era mais forte que tudo isso, era como as catingueiras e as baraúnas. Ele, sinhá Vitória, os dois filhos e a cachorra Baleia estavam agarrados à terra. (RAMOS, 1965, p. 21)

Bem, seria possível seguir até o infinito demonstrando como a metáfora "bicho" também não logra encerrarse e tem de ser substituída por uma metáfora botânica nesse trecho ("criara raízes, estava plantado"; "era como as catingueiras e as baraúnas”), mas parece que o argumento já está suficientemente maduro. Estamos um pouco distantes da adaptação "genética" da qual fala Marli Scarpelli (2007, p. 198). Os viventes não se adaptam à natureza por terem um laço originário com ela, mas em razão de uma insuficiência linguística. Esse processo é fruto de um mecanismo que Fabiano nem controla nem possui, mas que determina suas adaptações. Elas não são genéticas e sim mecânicas, interruptas. Por ser tão arbitrá rio quanto o nome "homem", o nome "bicho" é trocado implicitamente por "árvore", e o ciclo pode se prorrogar infinitamente. "Bicho" se consagra como nome próprio, em oposição ao figurado, assim como "Fabiano". E, assim como "Fabiano", esse nome próprio é uma 
12. Sobre o antropomorfismo como essa cristalização arbitrária da figuralidade, ver ou CHASE, 2007. imposição arbitrá ria que, como tal, demanda suplementação por um nome figurado. Seria "Fabiano" o único nome que não é uma metáfora, que tem um sentido literal, logo é a origem de toda cadeia de substituições no trecho - neste caso, estaria Graciliano invertendo o modelo de Rousseau? Ora, a postulação de "Fabiano", em si, não significa nada, afinal precisa ser suplementada por um processo metafórico que o identifica a "homem". A figura é o suplemento do ato, mas ela é incapaz de encerrá-lo, tendo de ser substituída por outra coisa. Logo, assim como "Fabiano" se torna "homem", "homem" também se torna "Fabiano" no sentido de esse nome desempenhar o mesmo papel daquele ao qual vem substituir. O nome próprio, a que toda figura está sujeita a se tornar, é apenas uma postulação sem sentido. Sujeita a essa cristalização, a figura se pretende estável ao ser antropomorfizada, com o que deixaria de ser figura - o que é um erro. ${ }^{12}$ Isto porque, assim como em Rousseau, os nomes em Vidas Secas não passam de hipóteses.

Assim, por meio de uma arbitrariedade Fabiano pode realizar outra. Por meio de uma linguagem fictícia, metafórica, ele inventa que pode passar "para fora" da denominação e da relação consigo mesmo (sem perceber que se repete em suas maquinarias o tempo todo). A inserção de Fabiano na maquinaria da linguagem é transposta metaforicamente para a maquinaria da sociedade ou do mundo natural. Por meio de uma ficção, Fabiano finge que sabe quem é, e por meio de outra, finge que sabe o que está fazendo no mundo Isso não é um problema só dele, é uma condição linguística. Não cabe aqui analisar o que Fabiano sofre na sociedade de classes, algo que já foi muito bem analisado por comentadores com compreensão muito superior à minha em sociologia. Cabe entender apenas que a ficção aqui possui um papel não de conhecimento (porque Fabiano interrompe a alegoria sabendo pouco mais do que já sabia), mas de socialização. Essa socialização se dá por meio de um ato puramente linguístico, a transposição da dinâmica da denominação para o terreno da interação. Como tal, ela é um a to arbitrário que interrompe uma sequência sem propriamente encerrá-la, e é incompatível com qualquer compreensão satisfa tória.

A performatividade da nomeação, portanto, é algo que se dá em uma relação tensa com sua dimensão figurativa. $\mathrm{O}$ destaque de um pode se dar apenas pela negação do outro. Isto é, para que Fabiano atue socialmente, ele deve passar por cima do caráter ficcional e metafórico de sua localização no social por meio de sua própria nomeação. Ao mesmo tempo, isso não estabelece de maneira alguma a precedência da linguagem figurada sobre a prática social. Não apenas as sucessivas correções operadas sobre a figuração já têm sua dimensão performativa, o início desse processo é também performativo. O momento da metáfora e da denominação 
13. Cf. ALTHUSSER, 2001, p.133-151.

14. "from a linguistic model that exists independently of nature and independently of the subject" ocorre em meio a uma situação prática, e é em si, como demonstrado, algo que irrompe em meio a ela. A relação entre as duas não é uma relação causal, mas contraditória, e ocorre no interior de um só a to de linguagem: Fabiano se procla ma "homem", "bicho" e "árvore".

A linguagem da ficção, a linguagem figurada, se mostra por excelência como a linguagem que reproduz o processo pelo qual os homens entram em sociedade. Foi Louis Althusser e não Graciliano Ramos nem Paul de Man quem demonstrou que o ingresso na sociedade e na história se dá por meio da inserção na linguagem ${ }^{13}$. E isso se dá por meio do erro e não do acerto, pela interrupção e não pela fluência. Podemos dizer junto a Paul de Man que a linguagem a partir da qual o homem estabelece sua relação em sociedade se estrutura como a da ficção, e que a política em geral deriva "de um modelo linguístico que existe independentemente da natureza e independentemente do sujeito" (DE MAN, 1979, p. 156; nossa tradução) ${ }^{14}$. Isso reforça o caráter político da linguagem literária, mas não porque ela transmite ou traduz uma determinada tensão social, mas justamente o contrário. $\mathrm{O}$ ato de socialização coincide com a metaforização cega que inaugura a ficção na qual esse ato pode ocorrer. Não nos permitamos enganar pela forma narrativa segundo a qual ocorre essa sequência e Fabiano passa do ato de denominar a si para a transposição desse a to à vida social. Ambas coisas são concomitantes.

Junto também a de Man, podemos dizer que a ficção é o a to político por excelência, mas não por ela vir de fora para intervir na política. Se a socialização depende de uma relação contraditória e arbitrária entre homem e linguagem, em primeiro lugar, a linguagem não pode ser algo que se sintetiza perfeitamente com o homem ta mpouco se permite estabelecer em uma relação reversiva de negação, logo não pode ser aquilo que determina direta mente a política. Antes, a política é determinada por uma série de contradições, uma das quais aquela entre homem e sua linguagem, da qual decorre uma entre linguagem e socialização, logo comunicação, por tabela. Antes de ser um ponto no qual o homem se realiza e ma nifesta todo seu potencial, a vida em sociedade se torna um fardo e uma atualização de contradições latentes - sentença com a qual Graciliano Ramos muito provavelmente concordaria. A linguagem da ficção tampouco se parece com aquele sonho idílico no qual a poesia seria um ato de comunicação total. Ao contrário, ela se mostra como um ato arbitrário de transposição cindido internamente por interrupções e apagamentos em sua própria estrutura referencial. A relação complexa entre a linguagem e as contradições de ordem social e econômica pode receber iluminação desse ponto de vista Mais do que isso, percebe-se também por que as relações de 
Fabiano e sua família com seu meio são tão inconclusivas e angustiantes em Vidas Secas. Elas são em si mesmas as relações tensas e complexas segundo as quais se produz a própria socialização humana. Certamente a linguagem é um grande obstáculo para todos os membros da família retratada por Graciliano Ramos, mas isso não se deve à sua animalidade, já que a identificação dura muito pouco. Essa dificuldade acaba sendo não o símbolo de uma experiência histórica específica, mas o procedimento literário a partir do qual Graciliano Ramos destaca a própria condição linguística. $\mathrm{O}$ ato de postulação, que realiza aquilo que postula como linguagem, refletido pelo a to de postulação de Fabiano dia nte de si mesmo. E assim como esse narrador se distancia das personagens que postula, Fabia no ta mbém acaba impondo uma distância entre si e a figura que o nomeia, mas todas são inseparáveis nessa contradição. Quando Fabiano se nomeia e assim se permite socializar, esse ato ta mbém o deforma. $\mathrm{O}$ a nimal e a árvore que Fabiano antropomorfiza para poder socializar não são manifestações de sua interioridade; são pura exterioridade que postula uma identificação incerta em nível de substância.

A tensão política em Graciliano Ramos, portanto, não se apresenta na forma da contradição entre uma subjetividade e uma superfície, entre interioridade e exterioridade, mas na passagem de uma para a outra e em sua instabilidade. Essa é uma contradição entre homem e sua linguagem. A socialização só pode ser compreendida sob o pano de fundo dessa complexa e contraditória relação linguística. Longe de ser um ato harmônico que sintoniza em identidade uma variedade de planos, a linguagem literá ria revela duas coisas. Em primeiro lugar, sua mecânica autorreflexiva; em segundo, a tendência dessa mecânica a se projetar de maneira imprópria para fora de si. Não é possível evitar que se refira e organize o mundo com a linguagem, mas esse processo perma nece impróprio e instável, ja mais em perfeito acordo com aquilo que designa. série de contradições impropriamente denominadas como harmonizações. A crença de que há uma coincidência ou simetria entre o nome que designa e aquilo que se designa é o que se chama por ideologia, o erro sem o qual nenhuma sociedade pode existir. A tendência definidora da linguagem é justamente a de evitar ser suprassumida e recuperada por sua referência ao mundo real. Evidentemente, toda linguagem significa e refere, mas não é possível que um conjunto de nomes corresponda de maneira unívoca à realidade, coisa que a insuficiência das categorias linguísticas exibidas no trecho de Graciliano Ramos demonstra muito bem. $\mathrm{O}$ ato de denominação encenado por Fabia no no segundo capítulo de Vidas Secas reproduz a relação contraditória da própria linguagem consigo mesma e com seus efeitos (sejam eles os indivíduos ou suas redes de socialização). Como tal, revela o ato de simultâneos obscurecimento e revelação constitutivo de 
toda linguagem como socialização. Assim sendo, o ato no qual se funda a socialização acaba sendo a transmissão enganosa de uma falsa harmonia onde há desarmonia. Essas tensões não são em nada descoladas das tensões de ordem social e econômica, a final há uma relação de determinação entre elas quando se fala em relação de trocas e valores, não estamos resguardados no terreno exclusivo dos nomes. Apenas uma narrativa de contradições e insatisfações, mas também de descontinuidades, como Vidas Secas, pode se desenvolver a partir daí; e a concepção de política que daí decorre só pode ser também uma teoria de enganos, falas pela metade, mas ta mbém de contradições, divisões e ausências.

\section{REFERENNCIAS}

ALTHUSSER, L.P. Lenin and Philosophy and Other Essays. 1st ed New York: Monthly Review Press, 2001.

CANDIDO, A. Ficção e Confissão: Ensaios sobre Graciliano Ramos. $3^{\mathrm{a}}$ ed. Rio de Janeiro: Ouro sobre Azul, 2006.

CARLOS, L. A. M.; LOPES, L. C. V. Do mítico ao lutador bemhumorado: 0 sertanejo na literatura brasileira. Odisseia - PPgEL/ UFRN. N. 9, 2012, p. 59-78.
CHASE, C. "Double-Take: Reading de Man and Derrida Writing on Tropes" in REDFIELD, Marc (Ed.). Legacies of Paul de Man. 1st ed. New York: Fordham University Press, 2007, p. 17-28.

DE MAN, P. Allegories of Reading: Figural Language in Rousseau Nietzsche, Rilke and Proust. 1st ed. New Haven: Yale University Press, 1979.

The Rhetoric of Romanticism. 1st ed. New York: Columbia University Press, 1984

The Resistance to Theory. Edited and with a foreword by Wlad Godzich. 1st ed. Minneapolis and London: University of Minnesota Press, 1986.

The Paul de Man Notebooks. Edited by Martin McQuillan. 2nd ed. Edinburgh: Edinburgh University Press, 2016.

RAMOS, G. Vidas Secas. $12^{a}$ ed. São Paulo: Livraria Martins Editora 1965

ROUSSEAU, J.J. Fuvres complètes. Vol. V: Écrits sur la musique, la langue et le théâtre. Coll. Bibliothèque de la Pléiade. 2éme ed. Paris: Editions Gallimard, 1996.

Jean-Jacques Rousseau: Do Contrato Social; Ensaio Sobre a Origem das Línguas. Vol. 1. $1^{\text {a }}$ ed. São Paulo: Editora Nova Cultural Ltda., 1999. 
SCARPELLI, M. O. F. Meio Ambiente e Literatura. Aletria: Revista de Estudos Literários, Belo Horizonte, v. 15, p. 188-204, 2007.

SOBRINHO, J. B. S. Fabiano e a bolandeira como máquina de criar subjetividades. Revista Texto Digital, Florianópolis, v. 10, n. 1, p. 163-173, 2014.

Recebido em: 03-11-2019.

Aceito em: 12-03-2020 